\title{
Evaluation of Root Nodulating Rhizobial Strains for Soybean Yield and Yield Components at Dangur District, North Western Ethiopia
}

\author{
Mamo Bekele Getachew Yilma Mesfin Kuma Tesfaye Midega Zewdineh Melkie \\ Ethiopian Institute of Agricultural Research, Pawe Agricultural Research Center
}

\begin{abstract}
Inoculating soybean seeds with superior rhizobia strains is necessary for nodulation and nitrogen fixation. Ironically, many commercial agricultural products (biological and chemical) claim increases in crop productivity but their efficacy cannot be guaranteed. Thus, the trial was conducted for two consecutive years during rainy seasons of 2014 and 2015 in order to determine the effectiveness of some commercial microbial inoculants and recommend the best thizobia that increase the soybean grain yield in study area (Dangur) district. The experiment consists of six strain bacteria, one inorganic fertilizer alone and negative control, totally eight treatments viz., SB14, SB-6B1, SB-6A2, SB-Murdock, SB-12, MAR-1495, recommended rate of fertilizer (100/ha TSP), and control treatment. The experiment was replicated three times in randomized complete block design. The results revealed that co-inoculation of SB-Murdock with the soybean variety Belesa 95, produced significantly higher grain yield per hectare $(1792.05 \mathrm{~kg})$, nodule numbers per plant $(105.7)$, nodules dry weight per plant $(0.51 \mathrm{~g})$, pod numbers per plant (36.57), seed numbers per plant (95.07) than the negative control treatment. On the other hand, the lowest grain yield $(1099.16 \mathrm{~kg} / \mathrm{ha})$, plant biomass $(3055.56 \mathrm{~kg} / \mathrm{ha})$, nodule numbers per plant $(4.73)$, nodule dry weights per plant $(0.04 \mathrm{~g})$, pod numbers per plant $(23.87)$ and seed numbers per plant $(55.3)$ were obtained from negative control treatment. The overall results thus suggest that rhizobial strains SB-Murdock can be used for producing higher yield of soybean when compared with the rest strain under agro climatic conditions of Dangur district.
\end{abstract}

Keywords: nitrogen fixaxion, Glycine max, nodules, inoculation.

DOI: $10.7176 / \mathrm{JBAH} / 10-16-01$

Publication date:August $31^{\text {st }} 2020$

\section{Introduction}

Soybean is one of legume crops produced mostly in werstern Ethiopia mainly in Oromia, Benishangul Gumuz and Seldom in Amhara regional state. It has various contributions in different area and its cultivation increase from time to time. It is used for both as feed and food crops, engine production and have great role as source of amino acids (Bekabil, 2015).

With the expectation of an increase in the amount of $\mathrm{N}$ used in agriculture due to increasing population and food demand, excess application of chemical nitrogen fertilizer and its negative impact on the environment can be reduced through biological nitrogen fixation (BNF) (Gupta et al. 2007). Amongst the principal aspects affecting the production of soybean is the suitable use of inoculums (Pagano and Miransari, 2016).

Biological nitrogen fixation is enhanced through inoculation. According to Qureshi et al., (2009), rhizobium legume inoculation has been practiced in agricultural systems for more than a century. Such inoculants can also be simply termed as bio-fertilizers (Mulongoy et al., 1992). Bio-fertilizers are valuable to the environment as they enable reduced use of chemical fertilizers in the production of crops in different parts of the world. They are defined as products containing natural occurring micro-organisms that are artificially multiplied to improve soil fertility and crop productivity (Mazid and Khan, 2014).

Insufficient use of inorganic fertilizers in sub-Saharan Africa (SSA) mainly because of accessibility challenge has contributed to nutrient depletion and consequently land degradation (Graham and Vance 2003); availability of bio-fertilizers were available, they would partially offer a potential solution to the issue as they are considered cost-effective (Ghosh, 2003). Continuous use of bio-fertilizers enables the microbial population to remain and build up in the soil and helps in maintaining soil fertility contributing to sustainable agriculture (Choudhury and Kennedy 2004; Malik et al., 2011). Growing crops using bio-fertilizers is advantageous in protecting the soil from degradation. The nitrogen fixation from symbiosis between rhizobia and legume is a cheaper source of nitrogen and legume inoculants is usually more effective agronomic practice for ensuring an adequate supply of nitrogen for legume-based crops (Zahran, 1999).

The effectiveness of Legume-Rhizobium symbiosis depends upon the specificity of rhizobial strains and responses of host plant. Generally $100 \mathrm{~kg} /$ ha nitrogen can be expected through Legume-Rhizobium symbiosis if the conditions are moderately favorable (Vincent, 1974). In case of soybean- Bradyrhizobium symbiosis, it fixes the atmospheric nitrogen within the root nodules and provides it to the host that plays the crucial role in growth and development of the host plant. Hence, updating the best effective rhizobia strain for soybean is important from time to time for increasing the productivity and yield of it. Therefore, the objective of this trial was aimed to select 
the best effective soybean strain bacteria for the purpose of increasing soybean grain yield.

\section{Materials and methods}

\subsection{Description of the study area}

The trial was carried out at Benishangul Gumuz Regional state of Metekel zone Dangur district, Ethiopia during rainy season for two consecutive years 2014 and 2015, where soybean is highly producing. It has the hot humid agro ecology, maximum rainfall of $1587 \mathrm{~mm}$, the maximum and minimum temperature is 32.6 and $16.3^{\circ} \mathrm{C}$ respectively and having nitosol types where physical and chemical status of initial soil sample of the experimental site was organic matter (\%):2.633, available phosphorus BrayII (ppm):0.7, organic carbon (\%):1.53, soil pH: 6.06 . The Randomized complete block design with eight treatments $(\mathrm{T} 1=\mathrm{SB}-14, \mathrm{~T} 2=\mathrm{SB}-6 \mathrm{~B} 1, \mathrm{~T} 3=\mathrm{SB}-6 \mathrm{~A} 2, \mathrm{~T} 4=\mathrm{SB}-$ Murdock, T5=SB-12, T6= MAR-1495, T7= Recommended rate of fertilizer (100/ha TSP), and T8= control) each replicated three times were used.

\subsection{Land Preparation, Inoculation and other agronomic practices}

Soybean (Glycine max) variety (Belesa95) is a medium set, high yielding variety, widely cultivated in Dangur districts was used as a test crop. The experimental site which have no history of inoculation and low nitrogen content was selected and land preparation was done following the conventional practice to make the field suitable for planting during mid- May and early June and then the land was leveled and divided into blocks and individual plots. The plots were kept $1 \mathrm{~m}$ apart with $1.5 \mathrm{~m}$ spacing between blocks. Canals were prepared around each plot making the plots beds. Carrier-based inoculants of each strain, obtained from HARC, were applied at the rate of $10 \mathrm{~g}$ inoculant $/ \mathrm{kg}$ seed. In order to ensure that all the applied inoculum stick to the seed, the required quantity of inoculant was suspended in 1: 1 ratio in 10\% sugar solution. The thick slurry of the inoculants was gently mixed with dry seed so that all the seeds received a thin coating of the inoculants. All inoculations were done just before planting under shade to maintain the viability of bacterial cells. Seeds were allowed to air dry for a few minutes and were then sown at the required rate and spacing. Plots with uninoculated seeds were planted first to avoid contamination. The inoculated and uninoculated seeds were then planted at $60 \mathrm{~cm}$ between row spacing and $5 \mathrm{~cm}$ between plants in the first week of July and drilled in the prepared rows per plot by hand, immediately covered with soil after sowing to avoid death of cells due to the sun's radiation and thinned after two weeks. Hand weeding was done three times at the interval of 30 days after sowing.

\subsection{Sampling procedures and observations}

Data on nodulation were recorded from five the second border rows of randomly selected plants at the flowering stage from each plots. Five plants were carefully uprooted randomly from each plot using a spade so as to obtain the exact nodule numbers and nodule dry weight, so that no nodules were left in the soil. The adhering soil was removed by washing the roots with intact nodules gently with water over a metal sieve. The number of nodules per plant was determined by counting the number of nodules from all the five uprooted plants per plot and then averaged as per plant. Finally, the nodules collected from the five plant samples from each plot were pooled, and their dry weight was determined by drying the nodules at $70^{\circ} \mathrm{C}$ for $72 \mathrm{hrs}$ to constant weight, and the dry weight was reported as $\mathrm{g} / \mathrm{plant}$.

\subsection{Crop Yield and Agronomic Data Collection}

Five plants were sampled randomly at maturity from each plot, pods were counted for all the five plants, and the average value was reported as number of pods per plant. The numbers of seeds per plant were determined by counting from five randomly sampled plants, and the average value was recorded as number of seeds per plant. Soybean plants were harvested from each plot at physiological maturity leaving the two border rows on every each plots. Seed yield was obtained by adjusting the moisture level to $12.5 \%$ according to the formula indicated by Abebe (1979).

Adjusted grain yield $=((100-\mathrm{MC}) / 100-12.5) *$ grain yield

as follows and converted into $\mathrm{kg} / \mathrm{ha}$ : where $\mathrm{MC}$ is moisture content of soybean seeds at the time of measurement, and 12.5 is the standard moisture content of soybean seeds at harvest in percent. The weights of hundred seeds randomly counted from the seeds of each plot maintaining the seed moisture content at $12.5 \%$ were reported as hundred seeds weight.

\subsection{Statistical Analysis}

The collected data were subjected to analysis of variance (ANOVA) in Randomized Complete Block Design (RCBD) replicated three times using statistical analysis systems (SAS) software (SAS., 2009). General linear model (GLM) was employed and treatment means were compared using Least Significant Differences (LSD) by Fisher's test at 0.05 . 


\section{Result and Discussion}

Based on the research done the following table describe the result obtained in a table form.

Table 1: Effects of different rhizobial strains on nodule numbers and yield and yield components of soybean

\begin{tabular}{lllllll}
\hline Treatments & $\begin{array}{l}\text { Nodule } \\
\text { number/ } \\
\text { plant }\end{array}$ & $\begin{array}{c}\text { Nodule dry } \\
\text { weight/g/ }\end{array}$ & $\begin{array}{l}\text { Pod } \\
\text { number/ } \\
\text { plant }\end{array}$ & $\begin{array}{c}\text { Seed } \\
\text { number/plant }\end{array}$ & $\begin{array}{c}\text { Stover yield } \\
(\mathrm{kg} / \mathrm{ha})\end{array}$ & $\begin{array}{l}\text { Grain } \\
\text { yield }(\mathrm{kg} / \mathrm{ha})\end{array}$ \\
\hline SB-14 & $63.67^{\mathrm{bc}}$ & $0.25^{\mathrm{bcd}}$ & $36.37^{\mathrm{a}}$ & $92.33^{\mathrm{a}}$ & $4509.26^{\mathrm{a}}$ & $1751.51^{\mathrm{ab}}$ \\
SB-6B1 & $79.93^{\mathrm{abc}}$ & $0.46^{\mathrm{ab}}$ & $32.07^{\mathrm{ab}}$ & $83.83^{\mathrm{ab}}$ & $3907.41^{\mathrm{bc}}$ & $1471.33^{\mathrm{bc}}$ \\
SB-6A2 & $59.87^{\mathrm{c}}$ & $0.29^{\mathrm{bc}}$ & $32.30^{\mathrm{ab}}$ & $81.20^{\mathrm{ab}}$ & $3643.52^{\mathrm{c}}$ & $1294.03^{\mathrm{cd}}$ \\
SB-Murdock & $105.70^{\mathrm{a}}$ & $0.51^{\mathrm{a}}$ & $36.57^{\mathrm{a}}$ & $95.07^{\mathrm{a}}$ & $4337.96^{\mathrm{ab}}$ & $1792.05^{\mathrm{a}}$ \\
SB-12 & $61.07^{\mathrm{bc}}$ & $0.23^{\mathrm{cde}}$ & $30.73^{\mathrm{abc}}$ & $79.80^{\mathrm{ab}}$ & $3851.85^{\mathrm{bc}}$ & $1496.11^{\mathrm{bc}}$ \\
MAR 1495 & $89.63^{\mathrm{ab}}$ & $0.23^{\text {cde }}$ & $34.10^{\mathrm{ab}}$ & $88.73^{\mathrm{ab}}$ & $4097.22^{\mathrm{abc}}$ & $1626.42^{\mathrm{ab}}$ \\
100kg.TSP/ha & $10.20^{\mathrm{d}}$ & $0.06^{\mathrm{de}}$ & $26.90^{\mathrm{bc}}$ & $69.47^{\mathrm{bc}}$ & $3055.56^{\mathrm{d}}$ & $1251.88^{\mathrm{cd}}$ \\
Control & $4.73^{\mathrm{d}}$ & $0.04^{\mathrm{e}}$ & $23.87^{\mathrm{c}}$ & $55.30^{\mathrm{c}}$ & $3055.56^{\mathrm{d}}$ & $1099.16^{\mathrm{d}}$ \\
\hline C.V $(\%)$ & 41.97 & 67.97 & 20.0 & 21.8 & 11.62 & 16.12 \\
LSD & 29.46 & 0.20 & 7.49 & 20.81 & 523.34 & 280.94 \\
\hline
\end{tabular}

* Means followed by same superscripts within the same column are not significantly different at the $5 \%$ level of probability based on LSD; TSP = Tri-superphosphate;

\subsection{Effect of strains on Nodule numbers and Nodule dry weight}

The numbers of nodules per plants were influenced significantly by the different strain and it ranges from (4.7 to105.7). The maximum nodule numbers per plant(105.7) was obtained due to seed co-inoculated with SBMurdock which was higher than the control treatment but statistically similar to MAR 1495(89.63) and SB6B2(79.93) while have highly significant difference with control treatment (4.73) followed by recommended TSP alone (10.2), SB-6A2(59.87), SB-12(61.07 ) and SB-14(63.67). In line with this finding, Tamiru Solomon et.al (2012) has also reported significantly higher number of nodules/plant from strain TAL 379 as compared to un inoculated and stain TAL-378. Thus, the findings of this experiment is also in agreement with those of Slattery et al., (2004) who reported that Rhizobium leguminosarum bv viciae is responsible for effective nodulation of faba bean, lentils and field pea. Egamberdiyeva et al., (2004) have also investigated the effect of inoculation with Bradyrhizobium japonicum S-2492 on soybean nodulation. They observed positive effects on nodule number. Kavathiya and Pandey (2000) found 69 nodules plant-1 by inoculating mungbean seed with Rhizobium. On the other hand, the lowest nodule number per plant was obtained from control treatment (4.73). This means, the uninoculated control did not produce any nodule at all, and is an indication that native strains of Bradyrhizobium japonicum bacteria that could form symbiotic relation with soybean are absent in the soils of Dangur district. There was no nodule formation in the control treatment throughout the experimental period, indicating that there was no rhizobia nodulating soybean in the area (Antenah Argaw, 2014). Therefore, the current study revealed that, the strain SB-Murdock produced significantly higher number of nodules than all the rest treatment except MAR 1495 and SB-6B2. Nodule dry weight was significantly $(\mathrm{p}>0.05)$ affected by the co-inoculation of soybean variety (Belesa 95) and rhizobial strain (Table1). The highest nodule dry weight per plant was obtained when seed coinoculated with SB-MURD (0.51g) which is statistically similar to SB-6B1 $(0.46 \mathrm{~g})$. However, there are considerable significance differences when compared to all the rest treatments. Bhuiyan et al., (1998) stated that inoculation with Rhizobium increased nodule dry weight. Furthermore, the lowest nodule dry weight acquired from un-inoculated (control) treatment $(0.04 \mathrm{~g} / \mathrm{plant})$ followed by un-inoculated inorganic fertilizer input $(0.06 \mathrm{~g} / \mathrm{plant})$. The maximum and minimum nodule dry weight was $0.19 \mathrm{~g}$ and $0.06 \mathrm{~g}$ recorded from the plant inoculated with strain-J43 and non-inoculated plant respectively (Sultana et al, 2014).

\subsection{Effect of strains on pod and seed numbers per plant}

There are significant differences among the treatments. The highest number of pod per plant was obtained from seed inoculated with SB-Murdock (36.57). However, statistically almost similar with SB-14(36.37).Previous research findings also indicate that, the highest number of pods per plant (39.40) was produced when the crop was grown in both limed soil and bradyrhizobia inoculation (Workneh Bekere, 2013). This finding is also in line with reports of Malik et al., (2006) and Bhuiyan et al., (2008) who indicated more pod number per plant of soybean and mung bean with rhizobia inoculation than uninoculated treatment. Likewise, Antenah Argew, (2014) said that, the average number of pods per plant produced by the inoculated soybean plants was $30 \%$ higher than number of pods per plant produced by soybean plants in the control treatment. The maximum number of pod and seeds plant-1 was 43.58 and 75.66 obtained from the plant inoculated with strain-J43 (Sultana, 2014). On the other hand, the lowest number of pod per plant was obtained from control treatment (23.87). Similar results also obtained by Solaiman, (1999) in chickpea, Feng et al., (1997) in pea, Hoque and Haq (1994) in lentil. Poddar et al. (1999) carried out a field experiment with soybean and found that Bradyrhizobium inoculation had favorable effect on 
seed number per plant and yield.

\subsection{Effect of strains on grain yield and Stover yield of soybean}

The highest Stover yield (4509.26kg/ha) was obtained seed co-inoculated with strain SB-14 which is $47.6 \%$ more than the control treatment and same result obtained seed co-inoculated with SB-Murdock and MAR 1495 (Table 1). Antenah Argew (2014) has also described that, soybean plants treated with the UK isolate inoculation produced the highest total biomass yield, exceeding the total biomass yield produced by plants in the control treatment by about 47.3\%. Similar findings were reported by Douka and Xenoulis (1998) who have found that inoculated plants produced $77 \%$ more dry matter yield over the uninoculated plants. Nevertheless, the lowest stover yield obtained from control treatment $(1099.16 \mathrm{~kg} / \mathrm{ha})$. Likewise, the highest $(1792.05 \mathrm{~kg} / \mathrm{ha})$ and lowest $(1099.16 \mathrm{~kg} / \mathrm{ha}) \mathrm{grain}$ yield was obtained from SB-Murdock and control treatment. But statistically non significant output was acquired from rhizoba SB-14 and MAR 1495 (Table 1). Almost similar observation was made by Abaidoo et al., (2015). Legumefix, a rhizobia inoculant helps to boosts the natural population of beneficial nitrogen-fixing bacteria to form effective nodules that are responsible for effective biological nitrogen fixation and explains the over $100 \%$ increase in grain yield compared to the control (Chen 2008).

\section{Conclusion}

From the above study it can be concluded that seed co-inoculated with Bradyrhizobium japonicum enhanced the nodule parameters, yield and growth parameters like nodule numbers, nodule dry weight, and numbers of pods per plant, number of seeds per plant and grain yield per hectare. Despite the fact that the highest (nodule number per plant, nodule dry weight per plant and grain yield per hectare was obtained from most strain bacteria), seed inoculated with inoculants strain bacteria (SB-Murdock) was more remarkable and recommendable for all users and policy makers. Consequently, the authors recommend that, the concerned body had better put into consideration this promised strain bacteria for large scaling up and technology dissemination so as to bring food security. For an alternative use, strain bacteria (SB-14) can be recommended for soybean inoculum production at studied area. Finally, more efforts need to be done to popularize this cheap and eco friendly technology among resource poor farming community of the nation.

\section{Acknowledgements}

The authors express gratitude to Pawe Agricultural Research Center for facilitating the research work. Authors thankfully acknowledge the financial assistance from COMPRO II project. The authors also express their appreciation to Fitsum Merkeb, Gezahegn Tefera and Wubayehu G/Medihn for their technical assistance.

\section{Reference}

Abaidoo Robert, C., Ewusi-Mensah, N., and Asei, R. 2015. Response of Soybean (Glycine max L.) to Rhizobia Inoculation and Molybdenum Application in the Northern Savannah Zones of Ghana. J. Plant Sci, 3, pp.6470.

Abebe B., 1979. Agricultural Field Experiment Management Manual Part III, Ethiopian Institute of Agricultural Research, Addis Ababa, Ethiopia, 1979.

Anteneh Argaw, 2014. Response of Soybean to Inoculation with Bradyrhizobium spp. in Saline Soils of Shinille Plains, Eastern Ethiopia" EAJS. 8 (2): 79 - 90

Bekabil, U. T. 2015. Empirical review of production, productivity and marketability of soya bean in Ethiopia. IJUNESST, 8(1), 61-66.

Bhuiyan, M.A.H.; Khanam, D.; Rahman, M.M. and Ali, M.M. 1998. Variation in the symbiotic effectiveness of Bradyrhizobium strains on soybean. Bangla. J. Microbiol., 15: 25-30.

Bhuiyan, M. A. H., M. H. Mian, and M. S. Islam 2008. Studies on the effects of Bradyrhizobium inoculation on yield and yield attributes of mung bean. Bangladesh j. agric. Res. 33(3): 449-457.

Choudhury, A.T.M.A. \& Kennedy, I.R. 2004, "Prospects and Potentials for Systems of Biological Nitrogen Fixation in Sustainable Rice Production”, Biol. Fertil. Soils. 39(4): 219-227.

Douka, C. E. and Xenoulis, A. C. 1998. Symbiotic Nitrogen in Soybean as Influenced by Time of Inoculation. Biological Agriculture \& Horticulture: An I.J.Sustain Product. Syste. 16 (2): 107 - 116.

Egamberdiyeva, D; Qarshieva, D. and Davranov, K. 2004. The Use of Bradyrhizobium to enhance growth and yield of soybean in calcareous soil in Uzbekistan, J. P. I. Growth Reguln., 23: 54-57

Feng, Y.; Pan, C.; Wang, D.; Li, Y. and Wei, C. 1997. Isolation of nodule bacteria from Pisum sativum and the application of nitragine from the isolate. J. Trop. Sub Trop. Bot., 5(2):47- 53.

Ghosh, N. 2003, Promoting Bio-fertilizers in Indian Agriculture", Institute of Economic Growth University Enclave. India. http://www.ipni.net. Accessed 25 April 2015)

Graham, P.H. \& Vance, C.P. (2003), "Legumes: Importance and Constraints to Greater Use", Plant physiol., 131(3), 872-877. 
Gupta, R.P., Anu, K., \& Shammi, K. 2007, “Bioinoculants: A Step towards Sustainable Agriculture, New India Publishing. .

Hoque, M.M. and Haq, M.F. 1994. Rhizobial Inoculation and Fertilization of Lentil in Bangladesh. Lens Newsl. 21: 29-30 P.

Chen, 2008. "The combined use of chemical and organic fertilizers and/or biofertilisers for crop growth and soil fertility". Paper presented at the International Workshop on Sustained Management of the Soil-Rhizosphere System for Efficient Crop Production and Fertilizer Use 16 - 20 October 2006. Land Development Department, Bangkok 10900 Thailand, 2008.

Kavathiya, Y. A. and Pandey, R. N. 2000. Interaction studies on Meloidogyne javanica, Rhizobium sp. And Macrophomina phaseolina in mungbean. J. Mycol. Plant Path., 30: 91-93.

Malik, M. A., M. A. Cheema, H. Z. Khan and M. W. Ashfaq 2006. Growth and yield response of soybean (Glycine max L.) to seed inoculation and varying phosphorus levels. J. Agri. Res. 44(1):47-53.

Mazid, M. \& Khan, T.A. 2014. Future of Bio-fertilizers in Indian Agriculture: An Overview. IJAFR, 3, 10-23.

Mulongoy K., Gianinazzi S., Roger P.A. and Dommergues Y. 1992. "Bio-fertilizers: Agronomic and Environmental Impacts and Economics", In Biotechnology: Economic and Social Aspects: Issues for Developing Countries, E.J. DaSilva, C. Ratledge and A. Sasson (eds.), Cambridge University Press, 55-69.

Sultana, M. M., Haque, M. A., Reza, M. S. A., and Chowdhury, M. A. H. 2014. Performance of Rhizobia And Nitrogen on Nodulation Yield and N Uptake by Soybean in Saline Soil. Journal of Environmental Science and Natural Resources, 7(1), 215-226.

Pagano, M. C., and Miransari, M. 2016. The importance of soybean production worldwide. In Abiotic and Biotic Stresses in Soybean Production (pp. 1-26). Academic Press.

Poddar, A. K.; Hossain, M. B.; Chanda, M. C.; Islam, M. Z.; Mondal, N. and Rahman, M. 1999. Selection of effective Bradyrhizobial strains for soybean cultivation for environmental management of Brahmaputra Floodplain Soil. Bangladesh J. Environ. Sci., 5:56-60

Qureshi, M.A., Ahmad, M.J., Naveed, M., Iqbal, A., Akhtar, N. \& Niazi, K.H. 2009. "Co-inoculation with Mesorhizobiumciceri and Azotobacter chroococcum for Improving Growth, Nodulation and Yield of Chickpea (Cicerarietimum L.)", Soil and Environ. 28, 124-129.

SAS (Statistical Analysis System) Institute, 2009. SAS/STAT Online Doc ${ }^{\circ}$, Version 9.2. User's Guide, 2nd edition. SAS Institute Inc., Cary, NC, USA, 7886p.

Slattery, J.F.; Pearce, D.J. and slattery, W. J. 2004. Effects of resident rhizobial communities and soil types on the effective nodulation of pulse legumes. Soil Biol. Biochem. 36:1339- 1346.

Solaiman, A.R.M. 1999. Nitrogenase activity, yield and yield contributing characters of chickpea as influenced by Rhizobium inoculant in presence and absence of nitrogen. Bangladesh J. Sci. Tech. 1(1):141-144.

Tamiru Solomon, Lalit Mohan Pant, and Tsige Angaw, "Effects of Inoculation by Bradyrhizobium japonicum Strains on Nodulation, Nitrogen Fixation, and Yield of Soybean (Glycine max L. Merill) Varieties on Nitisols of Bako, Western Ethiopia," Soil Sci. Plant Nutr. 38(1). pp. 75-84, 1992.

Vincent, J.M. 1974. Root-nodule symbiosis with Rhizobium In A. Quispel (ed.), The Biology of nitrogen Fixation. North-Holland publishing company Amsterdam. 264-342.

Workneh Bekere, 2013, Liming Effects on Yield and Yield Attributes of Nitrogen Fertilizer and Bradyrhizobia Inoculated Soybean (Glycine max L.) Grown in Acidic soil at Jimma, South Western Ethiopia, Journal of Biology, Agriculture and Healthcare. 3(14):

Zahran HH 1999: Rhizobium-legume symbiosis and nitrogenfixation under severe conditions and in an arid climate.Microbiol. Mol. Biol. Rev., 63, 968-989. 